\title{
Choke Point in Mini Expansion Device for the Development of Portable Vaccine Kit
}

\author{
Elmer B. Dollera, Christine France C. Dablo, Godofredo B. Dollera, Jr., Hermes O. Nasara, Kyle \\ Bryan A. Maquiso
}

\begin{abstract}
Vapor compression refrigeration system is substantial to human comfort and needs that contributes to the progress mainly in agriculture, food preservation and in medical application. One of the applications that this study focused on is the study of the choke points in mini expansion device for the development of portable vaccine carrier kit. This study utilized a vapor compression refrigeration system, and aims to improve the system operation of a small-scale vapor compression refrigeration system by using spirally-arranged capillary tubes with five(5) different hydraulic diameters, namely; $0.20 \mathrm{~mm}, 0.25 \mathrm{~mm}, 0.30 \mathrm{~mm}$, $0.35 \mathrm{~mm}$ and $0.40 \mathrm{~mm}$. A $1 / 8$ horsepower vapor compression refrigeration system of a water dispenser is used as an experimental rig that supply the required refrigerant flow on the spirally-arranged expansion device. Guitar strings are used to reduce the hydraulic diameter of the commercially available capillary tubes. With the inserted guitar strings, the five(5) different hydraulic diameters in this study would be connected to the experimental rig. The data gathering method is developed by using a data logger and the fabricated spirally-arranged capillary tubes connected to the experimental rig. The determination of its lengths of choke point and the behavior of the pressure drop is measured during the different trials used for every hydraulic diameter of the spirally-arranged capillary tube. The mathematical equation that correlates the hydraulic diameters of the capillary tubes and their corresponding choke points is represented by the equation $y=-1,836.0 x^{2}+2,319.0 x^{-1}-1.7860$, where $y$ is the distance of the capillary tube choke point and $x$ is the hydraulic diameter of the fabricated spirally-arranged capillary tubes. This equation correlates the hydraulic diameter of a capillary tube to its corresponding choke point length with a value of $R^{2}=0.9947$.
\end{abstract}

Keywords: hydraulic diameter, capillary tube, distance of choke point, pressure drops.

Revised Manuscript Received on December 30, 2019.

* Correspondence Author

Elmer B. Dollera*, a professor of Mechanical Engineering Dept, Xavier University, Cagayan de Oro City, Philippines. Email: edollera@xu.edu.ph

Christine France C. Dablo, a registered Mechanical Engineer and a graduate of Mechanical Engineering Department, Xavier University, Cagayan de Oro City, Philippines. Email: tinedabs@gmail..com

Godofredo B. Dollera, Jr., a registered medical doctor of Camiguin General Hospital, Mambajao, Camiguin Province, Philippines. Email. Gdollera@yahoo. Com

Hermes O. Nasara, a registered Mechanical Engineer and a graduate of Mechanical Engineering Department, Xavier University, Cagayan de Oro City, Philippines.Email: nasarahermes@gmail.com.

Kyle Bryan A. Maquiso, a registered Mechanical Engineer and a graduate of Mechanical Engineering Department, Xavier University, Cagayan de Oro City, Philippines, Email: kylebm0909@gmail.com.

(C) The Authors. Published by Blue Eyes Intelligence Engineering and Sciences Publication (BEIESP). This is an open access article under the CC BY-NC-ND license (http://creativecommons.org/licenses/by-nc-nd/4.0/)

\section{INTRODUCTION}

$\mathrm{T}_{\mathrm{h}}$ is mainly used for comfort, health, preservation, manufacture, and other industrial resources. Since cooling systems are utilized in various fields, it also varies from its functions, size, and design from large to small scale vapor compression systems. One of its field applications is on medical purposes, which primarily stores medical items such as vaccines.

Vaccine carriers are used for keeping vaccines temperature of around $8^{\circ} \mathrm{C}$ during transportation period. It has a smaller volume that is suitable for the use of health workers during immunization campaigns and outreached services. Moreover, vaccine carrier utilizes the commercial refrigeration unit system for medical purposes. This study focuses on the behavior of the expansion device of the vaccine carrier in accordance with its pressure drop and choke point.

The expansion device regulates the refrigerant flow from high-pressure side to the low-pressure side of the refrigeration system. The saturation temperature drop is caused by the pressure drop, which enables it to boil off at the low temperature of the evaporator. Thus, the mass flow rate of the refrigerant is dependent to the pressure drop in the expansion device[1].

In addition, capillary tubes can be made of straight, helical or spirally-coiled, and also serpentine coiled, but this study focuses on the spirally-arranged capillary tubes. Hence, it can be accommodated in a small space which is suitable for a mini vaccine carrier. It effectively reduces the mass flow rate at a higher percentage compared to straight capillary tubes operating under similar conditions.

In this study, the behavior of the expansion device, specifically, the spirally-arranged capillary tube, in a mini vaccine carrier is the main focus. The behaviors shall be observed by setting spirally-arranged capillary tubes with different diameters in order to evaluate the effect of pressure drops and in line with the advancement of mini vapor compression systems.

To improve the data or system analysis of a refrigeration system in the development of a portable vaccine carrier kit[12], a spiral-arranged capillary tube with different diameters are to be used.

\section{A. Specific Objectives}

i. To fabricate the five (5) spiral capillary tubes -0.20 Ømm, 0.25 Ømm, 0.30 Ømm, 0.35 Ømm, and 0.40 $\varnothing \mathrm{mm}$. The symbol, Ø, denotes hydraulic diameter. 
ii. To fabricate the experimental rig for the design of a vaccine carrier kit and install the five(5)spirallyarranged capillary tubes with different hydraulic diameters.

iii. To correlate the relationship between the diameter and

the lengths of the capillary tube with their respective choke points.

iv. To develop a mathematical model equation using the correlation of the hydraulic diameter and the lengths of choke point in a spirally-arranged capillary tube.

\section{B. Significance of the study}

The findings of this study will contribute to the benefit of the society, considering that mini vaccine carriers play a significant role in medical areas by storing vaccines and other temperature- sensible medical items. The conditions require the need for an efficient vaccine carrier kit design and development. Thus, the authors aim to study the behavior of a spirally-arranged mini capillary tube, with different hydraulic diameters and for the use in a mini vaccine carrier. In order to understand thoroughly the correlation between the proposed hydraulic diameters and the lengths of the choke point, an experimental rig is fabricated in order to measure the different thermodynamic parameters of the expansion device. Thus, the results may be used as basis for designing an expansion device for a small-scale refrigeration system, such as in mini vaccine carrier kit.

\section{Scope and limitations}

The scope of the study covers only the measurement of the lengths of choke point of the fabricated spirally-arranged capillary tubes, in a refrigeration system of a mini vaccine carrier kit. Also, to create a mathematical model equation of the correlation between the capillary tubes' hydraulic diameters and the lengths of the choke point.

Furthermore, the study is limited only with the available tools and instruments in the Mechanical Engineering Laboratory Complex of Xavier University - Ateneo de Cagayan, Cagayan de Oro City, Philippines.

\section{Theoretical framework}

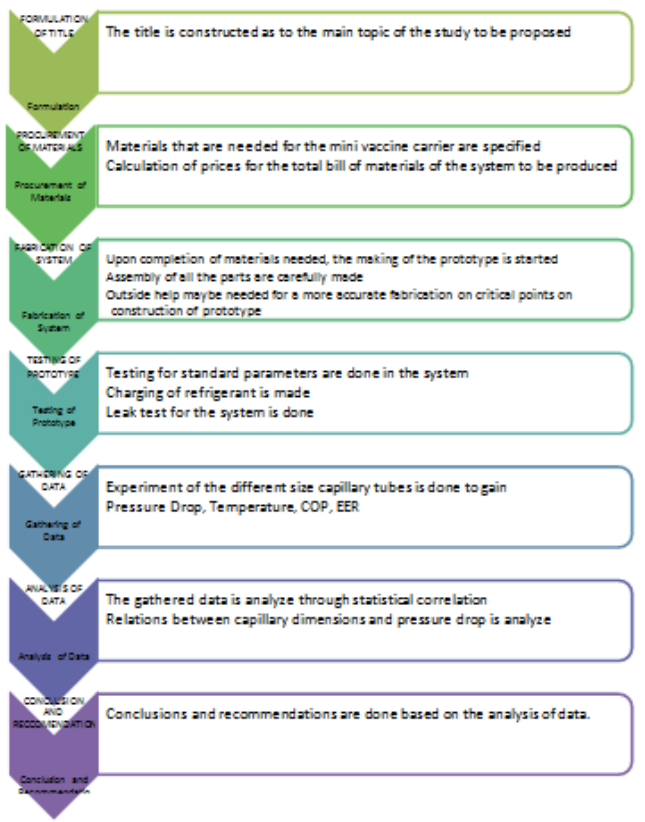

Fig. 1. Theoretical framework

\section{METHODOLOGY}

This section is about the processes and methods on how the study is conducted and performed. This includes the equipment and materials being used and the project design of the research study. The methods in fabrication are also discussed and described in this section.

\section{A. Research design}

The study was centered in obtaining the lengths of the choke point of the spirally-arranged capillary tubes and the behavior of pressure drops on the different capillary tubes. The main purpose of this, is for the development of the mini vapor compression system[2] and the mini vaccine carrier kit.

The procedures and the design that are necessary for the study are formulated below.

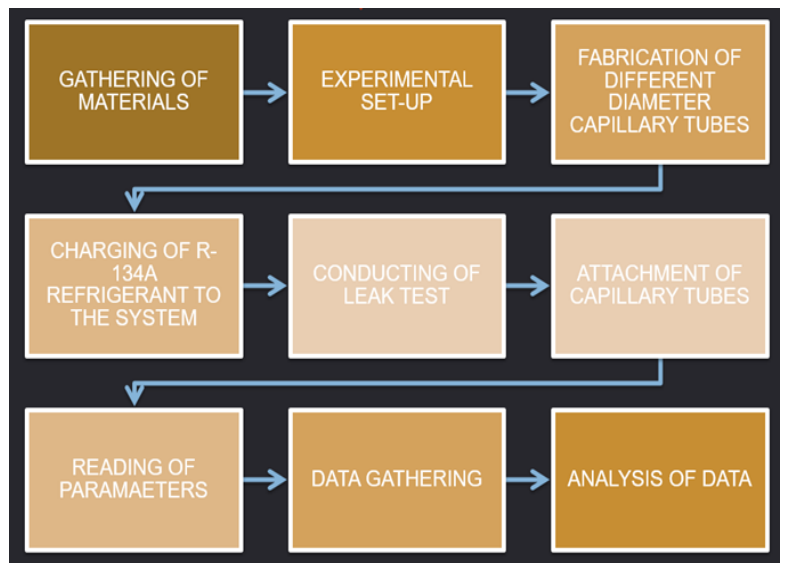

Fig. 2. Research design

In the design of the vaccine carrier kit, calculations were done such as the dimension and the lengths of the choke point of the refrigeration system. Computer aided drafting is used in the design of the casing. The casing was joined and assembled using rivets. A specific sample size of a vaccine bottle is used as a model for the dimension of the vaccine compartment.

The vapor compression refrigeration system is a modified design compared to the usual conventional system. This feature is necessary for the objectives to be achieved on time. A by-pass line for the capillary tubes, with gate valves, were added to the main system as shown in Fig.3.

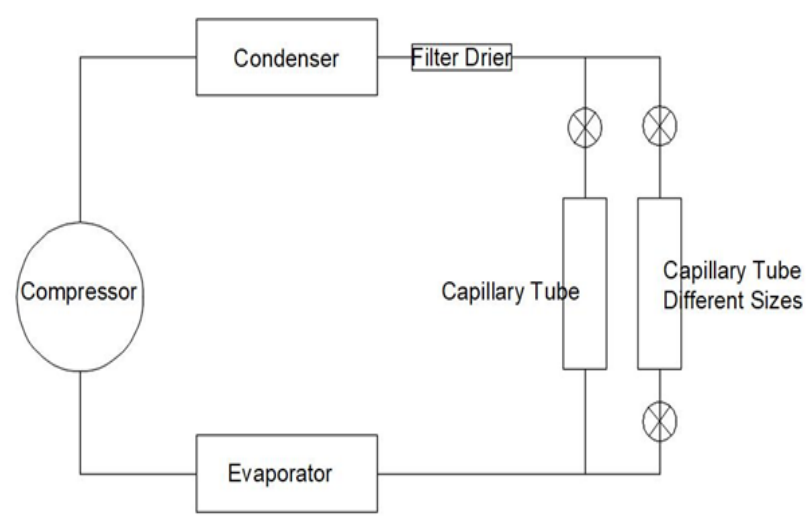

Fig.3. Experimental rig diagram 
In the fabrication of the different capillary tubes, the proper coiling of the capillary tube is necessary to attain a favorable result. Also, the use of the proper guitar string sizes that will be inserted inside the capillary tube is necessary. A fabricated copper " $T$ " $s$ " are used to connect the capillary tube to the line of the pressure gauges. After the connection is arranged, soldering process using oxygen acetylene welding and silver rod is done.

\section{B. Research process flow}

There are four major components in the mini vapor compression refrigeration cycle namely, the compressor, the condenser, the expansion valve and the evaporator. These four components are used in the fabrication and will be the measuring platform in conducting the experiment on the pressure drop data, the lengths of the choke point on the system, and the basis for the values for Energy Efficiency Ratio(EER) and the Coefficient of Performance(COP)[2].

The first stage of the study is the design of the vaccine carrier kit. This covers the dimensions of the case, the size of the storage and the calculation of the heat load of the vaccine carrier kit. The major parts of the vapor compression refrigeration system were also acquired for the assembly of the experimental rig[3]. The necessary materials were prepared, including the fabrication of the experimental rig and the capillary tubes with inserted guitar strings.

\section{Equipment and materials used}

The equipment and materials that are present in the study are the R-134a Hermetic type compressor, 3/16 " Condenser copper tubes, copper filter dryer, 1/8hp Capillary tubes, 1/4 " Evaporator copper tubes, gate valves, flow meter, and pressure gauges.

The R-134a Hermetic type compressor used in the study is taken from an old water dispenser. The compressor was first tested to determine if it is still functioning and have no defects for the fabricated refrigeration system. The fabrication of the whole system was cautiously done since the disadvantage of a hermetic compressor is that, it cannot be repaired. If the compressor fails due to mishandling or other factors, then the compressor must be replaced with a new model. However, the main advantage of a hermetic compressor is that it is sealed in a welded steel casing, so chances of gas leakages are almost impossible to occur[4].

The condenser copper tubes with $3 / 16$ " size is based on the original condenser of the water dispenser. The length and sizes also follows the original assembly of the compressor of the water dispenser. These dimensions are the most suitable design for the compressor. The researchers fabricated the same dimensions for the condenser with a new material but with a different wiring plot. The same idea is done in determining the dimensions of the designed evaporator. The evaporator copper tubes of 1/4 " size and length were based on the original dimensions of the water dispenser being used.

The filter drier is also made of copper and is suitable for the refrigerant R-134a. This kind of copper filter drier is used in various refrigeration unit. It has three orifices which is used for evacuation and charging of the refrigerant.

The capillary tube in the system uses a 1/8hp capillary tubes. This category determines that the capillary tubes are for $1 / 8$ horsepower compressors, which is the original name plate rating of the compressor being used. The length of the capillary tube is based on the length increment of the choke point. There are two passes of the capillary tubes, one is the main pass and the second one is the experimental capillary pass. The second passage is where the fabricated capillary tubes are attached with the flow meter to determine the lengths of the choking point of the system. The hydraulic diameters of the capillary tubes are, $0.20 \varnothing \mathrm{mm}, 0.25 \varnothing \mathrm{mm}$, $0.30 \varnothing \mathrm{mm}, 0.35 \varnothing \mathrm{mm}$, and $0.40 \varnothing \mathrm{mm}$ capillary tubes.

The gate valves that are used in the mini refrigeration system are connected at the end extension branch for the connection of the experimental capillary tubes. This gate valves holds the bypass of the refrigerant passing at the main capillary tube and the experimental capillary tubes. There are three(3) gate valves in the system, one(1) is attached to the inlet of the main capillary, and the other two(2) is located on the inlet and outlet of the experimental capillary tubes.

The flow meter is attached to the system, consists of one unit only, and attached at the end of the spiral capillary tube. When the flow meter of the capillary tube indicates zero or no refrigerant flow, then the system achieved the choking point of refrigeration system.

The pressure gauges that are attached to the system consist of six(6) units. Two pressure gauges are on the high side(red) of the system and the other four are located on low side(blue) of the system. One high side gauge is attached and on low side gauge is attached the main refrigeration system. The other four(4) gauges are attached to the fabricated experimental capillary tubes. The extra one(1) high side gauge is attached at the inlet of the capillary tube, another on attached after the filter drier, another two(2) extra low side gauges in between the sections of the capillary tube and one(1) extra low side gauge at the outlet of the capillary tube. This provides four(4) pressure readings in every capillary tube experimental test rig[5].

The thermostat in the system is attached to the compressor. The purpose of the thermostat is for the regulation of the operating temperature of the refrigerant on the compressor.

The casing of the mini vapor compression system is made of galvanized steel grade 00 . The sheets are joined with rivets at the edges. The whole casing has a dimension of $12 " \times 8 " \times$ 15 inches as shown in Fig.4. The inside compartment is about 6 inches in diameter and 4.3 inches in height.

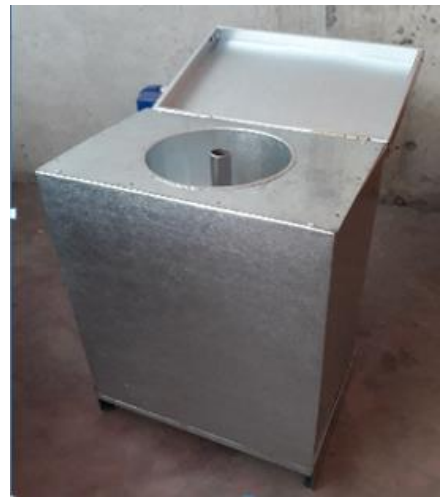

Fig. 4. Casing for the portable vaccine kit

\section{Fabrication of the experimental rig}

The first step of the fabrication is the assembly of the casing. The casing was designed in a rectangular prism just like the commercial vaccine carrier kit that is used in health centers. 
The dimensions are considered to fit the major components of a refrigeration system and to fit other components needed such as, pressure gauges and custom connections. These components are the measuring device used to gather the data.

The casing of the system uses galvanize steel plate and riveted to fix the parts.

The first component to be attached to the system is the compressor. The compressor is the heart of the refrigeration system and need to be placed first because of its size and weight.

After the compressor, the condenser is inserted to its line in the system[10]. The same way is done to the evaporator. Two(2) pressure gauges are attached, one on the high side pressure and another in the low side pressure. MAPP gas and silver rod is used to connect the copper tubes for the refrigeration system. Three gate valves are attached to the system, the purpose of the first one is for the main capillary tube, and the two other is for the experimental capillary tube. After the assembly, the system is charged with tetraflouroethane refrigerant and uses soap to test for the leakage of the system. After a successful leak test, the system is ready for the experimentation of capillary tubes.

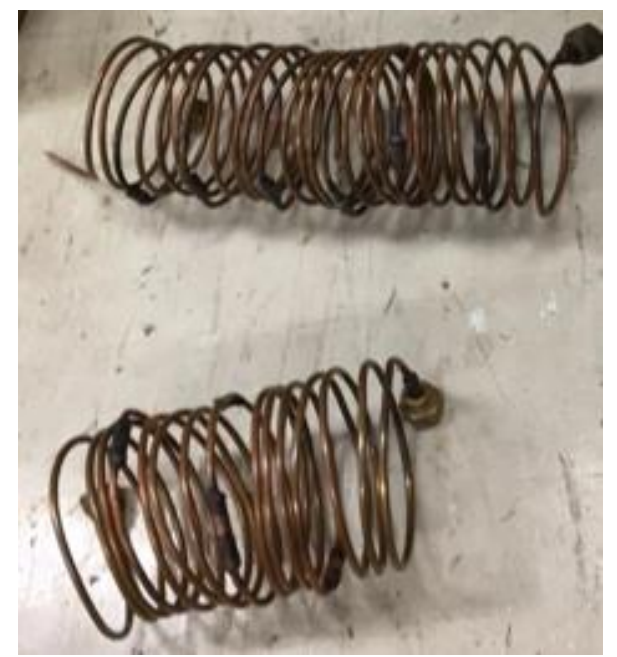

Fig. 5. Spiral coil of capillary tube

The first step in fabrication of the spiral capillary tube is the coiling of the copper tubes as shown in Fig.5. The use of a cylindrical object is necessary to attain perfect coil. A careful work is needed on this part, so that the diameter of the coils will not vary. The variation of the coils diameter may affect the data gathering of the experiment rig. After the coiling of the copper tubes, is the insertion of the guitar strings inside the capillary tube. Proper number of strings is considered to achieve the desired diameter of capillary tubes. A knife and a long nose plier are used in cutting the capillary tube. Next step, is the fabrication of "T" connections. The drill bit tool is used in making a hole on one side of the copper tube, and inserting the other copper tube in upright direction, forming a "T"[6]. It is then soldered using MAPP gas and silver rod. Copper tubes with $1 / 4$ size are also needed in the fabrication since, it is attached to the $1 / 4$ flare nut. A total of five(5) flare nuts and one compression nut is attached to a single different size capillary tube.

\section{EXPERIMENTAL}

In designing the vapor compression refrigeration system, calculations are made using the appropriate engineering design formula. This includes the analysis of basic vapor compression refrigeration cycle that are plotted in the temperature - entropy diagram and pressure - enthalpy diagram. Property conditions are set to conceptualize in designing a refrigeration system. The evaporator temperature should be higher than the ambient temperature, which the authors designed around $45^{\circ}$ Celsius. The evaporator temperature is the temperature requirement in order to remove heat from the confined space, or in the designed vaccine compartment[12]. The refrigerant being used is $\mathrm{R}-134 \mathrm{a}$ having a chemical name of tetrafluoroethane, as it is among the best refrigerant today. Tetraflouroethane refrigerant is harmless, available in the market and has an insignificant ozone depletion potential.

In the compressor inlet (State 1), the properties to be considered for the refrigerant is $2{ }^{\circ}$ Celsius temperature and is saturated vapor. In continuing the calculation using R-134a property tables and chart, the values of pressure $(314.44 \mathrm{kPa})$, enthalpy (251.622 kJ/kg), and entropy (0.93 kJ/Kg-K) are obtained.

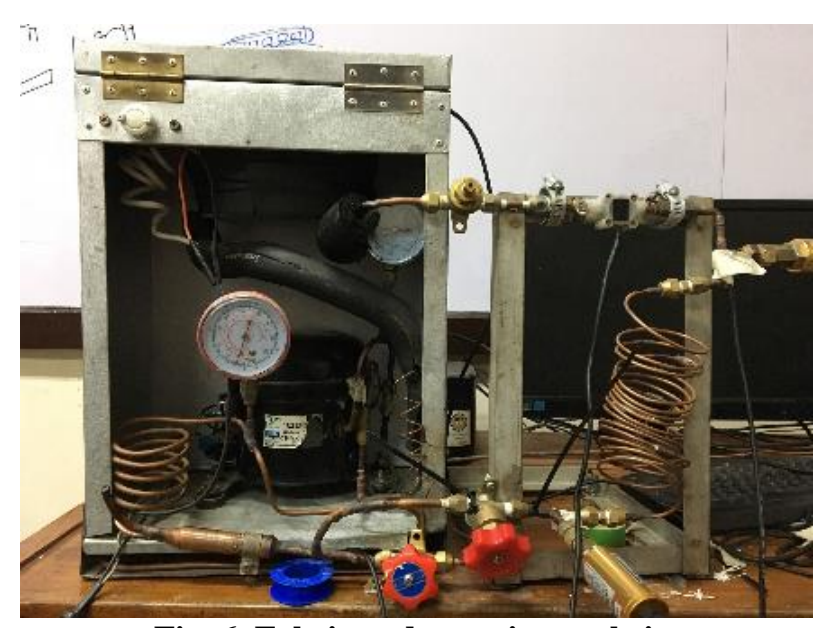

Fig. 6. Fabricated experimental rig.

The condenser outlet (State 3) properties are $45^{\circ}$ Celsius temperature and saturated liquid. Using property tables and chart again, the following properties of pressure (1162.32 $\mathrm{kPa})$ and enthalpy $(115.84 \mathrm{~kJ} / \mathrm{kg})$ are obtained.

In the State 4 of the system, the inlet of the evaporator, is a saturated liquid-vapor mixture. The enthalpy of this state is equal to the enthalpy of State 3, which is $115.84 \mathrm{~kJ} / \mathrm{kg}$. In the inlet of the condenser (State 2), the properties present is entropy, which is equal to State $1(0.93 \mathrm{~kJ} / \mathrm{kg}-\mathrm{K})$, and pressure equal with State $3(1162.32 \mathrm{kPa})$. Using a chart. The enthalpy of this state is obtained, which is approximately 280 $\mathrm{kJ} / \mathrm{kg}$. Acquiring all the enthalpy of each state proceeds to the calculation of the compressor work and Coefficient of Performance (COP) of the system.

\section{A. Data collection procedures}

The data will be gathered for 6 hours with 75 minutes for each capillary tube with an interval of 30 seconds[7,8]. The study needs at least 15 trials to get a more accurate result. 
Pressure gauges and thermocouples are used to measure the thermodynamic properties in the experimental rig as shown in Fig.6. The data will be gathered in conformation with the authors' testing procedures;

1. Before starting the whole system, make sure that the globe valve to the main capillary tube is open.

2. Make sure that all the elements used for the experimental capillary tubes are tightened to avoid the refrigerant flow.

3. After all other conditions are checked, start up the system and let it run for 10 minutes before gathering the data. This is to create a stable pressure inside the system.

4. After 5 minutes passing and on 10 minutes mark, start to take the reading of the flow meter. If the reading in flow meter indicates a zero value, then adjust the length of the capillary tube.

5. In adjusting the value of the spiral capillary tube, a 1 cm increment is used. Using a long nose plier, cut the said increment from the experimental capillary tube.

6. Attach the adjusted capillary tube back to the system using a MAPP gas and a silver rod.

7. Repeat process 3 until you acquire a non-zero flow meter reading.

8. Record the length of the spiral capillary tube as soon as you attain the non-zero flow on the flow meter.

9. Start to take the reading in the pressure gauges, starting from the high side pressure gauge to the low side pressure gauge. These readings will be annotated as $\mathrm{P}_{1}, \mathrm{P}_{2}, \mathrm{P}_{3}$, and $\mathrm{P}_{4}$ respectively.

10. The data will be gathered every 5 minutes interval, up to 15 trials, the system will be running for about 75 minutes at 30 seconds interval in the data logger for one diameter of a capillary tube. This procedure will be repeated with the other sizes of capillary tubes[9,11].

11. After 15 trials of testing with the capillary tubes. Turn off the system and wait for it to stabilize by observing the main pressure gauges.

12. After all the system is stabilize, detached the experimental capillary tube and replace with another different size. Leaks happen at this part so charging it with refrigerant is needed.

13. Repeat the whole procedure for the next sets of capillary tubes.

\section{RESULT AND DISCUSSION}

In this section, the calculations, experimental data and the result are presented. The theoretical values and actual values are analyzed and discussed. This section also includes answers of the objectives of the study.

The measurement of the lengths of the choke point of the mini expansion device for the development of a portable vaccine carrier, spirally-arranged capillary tubes with different diameters are being used.

In improving the data analysis for the study, every hydraulic diameter and its thermodynamic properties are determined. In the experiment of $0.2 \varnothing \mathrm{mm}$ capillary tube, the following tabulated result is obtained with the measured values shown in Table 1.
Table 1. Temperature and pressure drop for $\mathrm{d}=\mathbf{0 . 4} \mathrm{mm}$

\begin{tabular}{|c|c|c|c|c|c|c|c|c|c|}
\hline \multicolumn{10}{|c|}{0.4} \\
\hline Sample & $\begin{array}{c}\text { P1 } \\
\text { BAR }\end{array}$ & $\begin{array}{r}\text { P2 } \\
\text { BAR }\end{array}$ & ${ }^{\mathrm{T} 1} \mathrm{C}$ & $\begin{array}{l}\mathrm{T} 2 \\
{ }^{\circ} \mathrm{C}\end{array}$ & $\begin{array}{l}\mathrm{T} 3 \\
{ }^{\circ} \mathrm{C}\end{array}$ & $\begin{array}{l}\mathrm{T} 4 \\
{ }^{\circ} \mathrm{C}\end{array}$ & $\begin{array}{c}\text { Flow } \\
(\mathrm{mL} / \mathrm{min})\end{array}$ & $\begin{array}{l}\text { Length } \\
\text { (cm) }\end{array}$ & $\begin{array}{l}\text { EXPERIMENTAL } \\
\text { CP LENGTH }\end{array}$ \\
\hline 1 & 11.95 & 2.97 & 51.3 & 8.73 & -2.6 & 34.92 & 16.9 & 558 & \multirow{5}{*}{598} \\
\hline 2 & 11.95 & 3.37 & 57.35 & 8.2 & 1.75 & 34.94 & 19.72 & 548 & \\
\hline 3 & 11.95 & 3.52 & 61.74 & 5.54 & -0.65 & 38.39 & 20.42 & 538 & \\
\hline 4 & 11.95 & 3.71 & 56.07 & 6.35 & 0.51 & 36.64 & 21.83 & 528 & \\
\hline 5 & 11.95 & 2.65 & 51.99 & 3.13 & -2.19 & 35.87 & 27.46 & 518 & \\
\hline
\end{tabular}

The pressure drop of the $0.40 \mathrm{~mm}$ capillary tube shows that the maximum pressure drop reaches 9.30 bar. The flow rate shows that the length of the capillary tube reaches $558 \mathrm{~mm}$. The table also shows that the flow rate of the $0.40 \mathrm{~mm}$ decreases as the length of the capillary tube is increased.

Table 2. Percentage error

\begin{tabular}{|c|c|c|c|}
\hline $\begin{array}{c}\text { DIAM TER } \\
\mathbf{m m}\end{array}$ & $\begin{array}{c}\text { THEORETICAL } \\
\text { LENG TH } \\
\mathbf{c m}\end{array}$ & $\begin{array}{c}\text { EXPERIMENTAL } \\
\text { LENG TH } \\
\mathbf{c m}\end{array}$ & $\begin{array}{c}\text { PERCENT } \\
\text { ERROR } \\
\%\end{array}$ \\
\hline 0.2 & 393.15 & 349 & 12.6504298 \\
\hline 0.25 & 452.06 & 432 & 4.643518519 \\
\hline 0.3 & 534.77 & 522 & 2.446360153 \\
\hline 0.35 & 588.02 & 566.3 & 3.835422921 \\
\hline 0.4 & 629.53 & 598 & 5.272575251 \\
\hline
\end{tabular}

1.To fabricate the five (5) spiral capillary tubes -0.20 Ømm, $0.25 \varnothing \mathrm{mm}, 0.30 \varnothing \mathrm{mm}, 0.35 \varnothing \mathrm{mm}$, and $0.40 \varnothing \mathrm{mm}$. The symbol, $\varnothing$, denotes hydraulic diameter.

The fabrication of the capillary tubes with different hydraulic diameters was the most challenging part. The guitar string insertion required a careful act because if the string is accidentally bent, the crease will no longer be healed. A different string should be replaced if such action occurs. Also, insertion of multiple strings is a difficult task because guitar strings tends to stuck if it is not done in a right way.

Another challenging part in the fabrication is soldering of the copper tubes and to attach the incremental length needed for fabrication. Despite the challenges, the problems were solved and the capillary tubes were successfully fabricated.

2.To fabricate the experimental rig for the design of a vaccine carrier kit and install the five(5) spirally-arranged capillary tubes with different hydraulic diameters.

The design of the measuring platform is a basic refrigeration system which is installed in a vaccine carrier case design. The design is inspired by a vaccine carrier used in health centers for rural areas, with a rectangular prism body. The installation of the capillary tubes in the system is on alternate or take turn basis. The first capillary tube will be installed, after doing the experiment, it will be removed and replaced with another experimental capillary tube. This kind of installation for the measuring platform is designed to attain the compactness of the system and can be installed in the mini vaccine case.

Thus, the fabrication design of the measuring platform installed in a vaccine carrier is completed.

3.To correlate the relationship between the hydraulic diameter and the length of the capillary tube and their respective choke point.

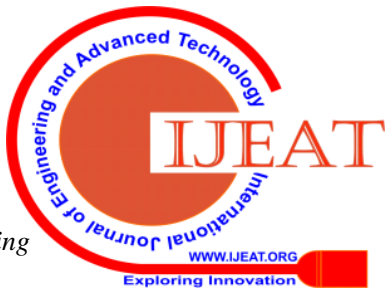


In correlating the relationship between the hydraulic diameter and the length of the choke point on the capillary tube, a graph is made to visualize the data and an equation is formulated to further enhance the understanding of the curve.

The line shows that the flow rate in terms to the length of the $0.20 \mathrm{~mm} \varnothing$ capillary tube is equal to $\mathrm{y}=0.0048 \mathrm{x}^{2}-$ $3.3768 x+602.12$, where $x$ is the length of the capillary tube choke point and its $\mathrm{R}^{2}$ is equal -0.979 which means that the data is strongly correlated.

The graph also shows that as the length of the capillary tube increases, the flow rate inside the capillary tube approaches to zero. The empirical length of the choke point is calculated with the equation above is $393.15 \mathrm{~cm}$. For a length of choke point of $359 \mathrm{~cm}$, the percent error is $9.51 \%$.

Table 3. Temperature and pressure drop for $\mathrm{d}=\mathbf{0 . 2 0} \mathrm{mm}$

\begin{tabular}{|c|c|c|c|c|c|c|c|c|c|}
\hline \multicolumn{10}{|c|}{0.2} \\
\hline Sample & $\begin{array}{c}\text { P1 } \\
\text { BAR }\end{array}$ & $\begin{array}{r}\text { P2 } \\
\text { BAR }\end{array}$ & $\begin{array}{l}{ }^{\mathrm{T} 1} \\
{ }^{\circ} \mathrm{C}\end{array}$ & $\begin{array}{l}{ }^{\mathrm{T} 2} \\
{ }^{\circ} \mathrm{C}\end{array}$ & $\begin{array}{l}{ }^{\mathrm{T} 3} \\
{ }^{\circ} \mathrm{C}\end{array}$ & $\begin{array}{l}\mathrm{T} 4 \\
{ }^{\circ} \mathrm{C}\end{array}$ & $\begin{array}{c}\text { Flow } \\
(\mathrm{mL} / \mathrm{min})\end{array}$ & $\begin{array}{l}\text { Len } \\
\text { gth } \\
(\mathrm{cm})\end{array}$ & $\begin{array}{l}\text { EXPERIME } \\
\text { NTAL CP } \\
\text { LENGTH }\end{array}$ \\
\hline 1 & 11.95 & 2.5 & 45.2 & 0.07 & -3.9 & 37.01 & 19.01 & 319 & \multirow{5}{*}{349} \\
\hline 2 & 11.95 & 3.71 & 48.6 & 0.64 & -1.51 & 40.91 & 21.13 & 309 & \\
\hline 3 & 11.95 & 2.57 & 49.3 & -0.16 & 0.13 & 36.7 & 24.65 & 299 & \\
\hline 4 & 11.95 & 3.97 & 58.79 & 8 & 0.64 & 41.45 & 33.8 & 289 & \\
\hline 5 & 11.95 & 2.98 & 44.43 & 7.18 & 1.32 & 38.45 & 36.5 & 279 & \\
\hline
\end{tabular}

4.To develop a mathematical model using the correlation of the hydraulic diameters and the length of the choke points in a spirally-arranged capillary tubes.

The mathematical equation that correlates the hydraulic diameters of the capillary tubes and their corresponding choke points is represented by the equation as $\mathrm{y}=-1,836.0 \mathrm{x}^{2}$ $+2,319.0 x^{-1}-1.7860$, where $y$ is the length of the capillary tube and $\mathrm{x}$ is the hydraulic diameter of the fabricated capillary tubes. This equation correlates the diameter of a capillary tube to its corresponding choke point length with a value of $\mathrm{R}^{2}=0.9947$.

\section{Hydraulic Diameter vs Choke Point Length}

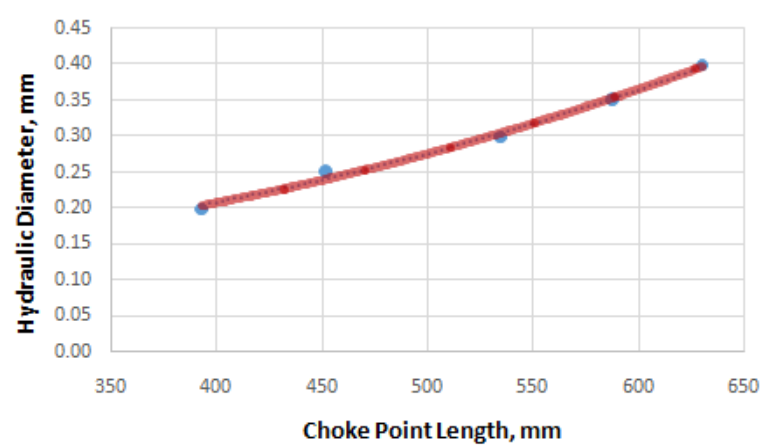

Fig. 7. Hydraulic diameter vs. choke point length in $\mathbf{m m}$

Based from the generated equation of the linear correlation for the length of the capillary tube choke point and its corresponding flow for each diameter, a matrix can be formulated as,
Where D is the hydraulic diameter of the capillary tube, therefore a general matrix is;

$$
\left[\begin{array}{l}
0.20 \\
0.25 \\
0.30 \\
0.35 \\
0.40
\end{array}\right]=\left[\begin{array}{l}
169.49 \\
89.056 \\
125.24 \\
190.52 \\
146.24
\end{array}\right]+\left[\begin{array}{l}
-0.4765 \\
-0.1970 \\
-0.1973 \\
-0.3240 \\
-0.2323
\end{array}\right] x
$$

\section{CONCLUSION}

The overall result of the experiment shows that the pressure drop from the capillary tubes of $0.2 \varnothing \mathrm{mm}, 0.25$ Ømm, 0.3 Ømm, $0.35 \varnothing \mathrm{mm}$, and 0.4 Ømm is dependent on the length and diameter of the capillary tube. The longer the length of the capillary tube, the higher the pressure drop, and in theoretical relationship, the lower the flow rate.

The authors also concluded that the bigger the diameter of the capillary tube, the longer the length to achieve the choke point. By curve fitting, the condition will be expressed as an empirical equation, $y=-1,836.0 x^{2}+2,319.0 x^{-1}-1.7860$, where $\mathrm{y}$ is the length of the capillary tube and $\mathrm{x}$ is the hydraulic diameter of the capillary tube.

\section{ACKNOWLEDGMENT}

Much has been done to accomplish this paper, and the authors are truly thankful for the help and support of many people, and to those who contributed in the fulfillment of this study.

Mr. Philip G. Cabading, for the valuable assistance extended to this study, by lending his tools and equipment used in data gathering.

To the unending moral and spiritual supports from our friends, who believed that this study will be finished on time.

To the authors' family, for the emotional supports they extended to the fulfillment of this study.

And finally, we wish to express our deepest gratitude to Almighty God, through the intercession of the Blessed Virgin Mary, for the gift of knowledge, talents and wisdom, and for giving the authors, the courage in times of difficulties until the time the study is completed. Ad Majorem Dei Gloriam!

\section{REFERENCES}

1. A. Bejan, "Advanced Engineering Thermodynamics", 2nd ed., New York: Wiley Interscience, 1997.

2. W. F. Stoker and J. W. Jones, "Refrigeration and Airconditioning," $2^{\text {nd }}$ edition. New York, McGraw Hill, 1982.

3. E.B.Dollera, and E.P. Villanueva, "A study of the Heat Transfer Coefficient of a Mini Channel Evaporator with $R-134 a$ as Refrigerant", IOP Conference Series: Materials Science and Engineering. Volume 88 012027, 2014.

4. ASHRAE, :"Handbook of Refrigeration”, SI Version, Atlanta, GA, American Society of Heating, Refrigerating, and Air-Conditioning Engineers, Inc., 1985.

5. E. B. Dollera, E. P.Villanueva, L.L.Pabillona, and R, C. Golez Jr., "Lockhart-Martinelle Correlation of Refrigerant $R-134 a$ Pressure Drop in Minichannel Evaporators", Australian Journal for Basic \& Applied Sciences(AJBAS), ISSN:1991-8178, Volume-9 Issue-37, Special Issue 2015, pp. 28-34. 
6. E.B.Dollera, R.C. Golez Jr., N.G. Ipanag, G.B. Dollera Jr., K. I. D. Liwanag, K. J. A. Dotdot, R.D.Z. Bagayas, and F. E. Joring "Comparative study of pressure drop on a micro expansion device for the development of a mini vaccine carrier", Global Scientific Journals(GSJ), ISSN: 2320-9186, Volume-7 Issue-8, August 2019, pp. 613-623,

7. J. F. Miraflor, E. B. Dollera, R. C. Golez Jr., N. G. Ipanag, Y. G. Melliza, R. J. A. Cañeda, "An Experimental Study of the Waste Heat Recovery for the Absorption Type Transport Airconditioning System", Global Scientific Journal(GSJ), ISSN: 2320-9186, Volume 7, Issue 9, September 2019, pp. 177-183.

8. $\quad$ E. B. Dollera, N. T. Corbita,Jr., M. J. S. Quitiol, J. S. Tagno-ay, J. M. Trazona, "XU Solar Furnace for Recycled Plastic Lumbers," International Journal of Scientific and Technology Research (IJSTR), ISSN:2277-8616(Online), Volume-8 Issue-10, October 2019, pp. 877-885,

9. E. B. Dollera, R. C. Golez Jr., S. D. R. C. Ty, J. P. F. S. Gaston, J. V. Balo, "Development of XU Plastic Shredder for Cost Effective Means of Minimizing Polyethylene Terephthalate Plastic Waste Volume", International Journal of Innovative Technology and Exploring Engineering(IJITEE), ISSN: 2278-3075(Online), Volume 8, Issue 12, October 2019, pp. 2821-2825,

10. L. L. Pabilona, E. P. Villanueva, and E. B. Dollera, "An Experimental and Simulation Study of Heat Transfer Coefficient of the Mini Channel Condenser for Refrigeration System", Australian Journal for Basic \& Applied Sciences(AJBAS), ISSN: 1991-8178(Online), Volume 9 Issue37, Special 2015, pp. 6-14,

11. E.B. Dollera, M. C. F. Rey, A. R. De Jesus, J. M. Piloton, R. R. Salem, Jr., "Water Desalination System using Parabolic Trough with Varying Glass Thickness", International Journal of Engineering and Advanced Technology(IJEAT), ISSN: 2249-8958(Online), Volume 9, Issue 1, October 2019, pp 6-11.

12. E. B. Dollera, E.P.Villanueva, L. L. Pabilona, K. J. A. Dotdot, G. B. Dollera, Jr., "Temperature Distribution in Mini Channel Hea Exchanger for the development of a Portable Vaccine Carrier," International Journal of Recent Technology and Engineering(IJRTE), ISSN:2277-3878(Online), Volume-8 Issue-4, November 2019, pp. $222-226$

\section{AUTHORS PROFILE}

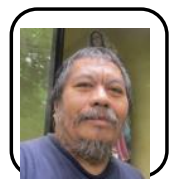

Elmer B. Dollera, is a registered Professional Mechanical Engineer of the Republic of the Philippines and currently working as a professor in Mechanical Engineering Department, Xavier University, Cagayan de Oro City, Philippines. He earned his degree in Doctor of Engineering in MSU-Iligan Institute of Technology(2015) and Master of Science in Mechanical Engineering (1995) in University of the Philippines, Quezon City, Philippines. He attended a Post Masteral Program in Mechanical Engineering (1997) in University of New South Wales, Sydney, Australia.

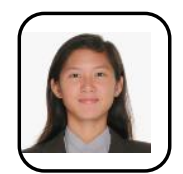

Christine France C. Dablo, is a registered Mechanical Engineer of the Republic of the Philippines and a graduate of Bachelor of Science in Mechanical Engineering(2018) in Xavier University-Ateneo de Cagayan, Cagayan de Oro City, Philippines.

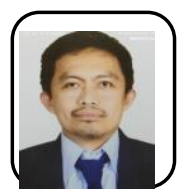

Godofredo B. Dollera, Jr., is a registered Doctor of Medicine of the Republic of the Philippines and is currently working as a general surgeon of the Department of Surgery in Camiguin General Hospital, Mambajao, Camiguin Province, Philippines. He earned his degree in Doctor of Medicine(1998) in Dr. Jose P. Rizal College of Medicine, Xavier University, Cagayan de Oro City and his degree in Bachelor of Science in Nursing(1994) in Xavier University, Cagayan de Oro City, Philippines. He is now working with his theses for the degree in Master in Hospital Management and Master in Business Administration in Jose Rizal University, Mandaluyong City, Philippines.

Hermes O. Nasara, is a registered Mechanical Engineer of the Republic of the Philippines and a graduate of Bachelor of Science in Mechanical Engineering(2018) in Xavier University-Ateneo de Cagayan, Cagayan de Oro City, Philippines.

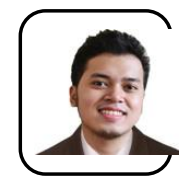

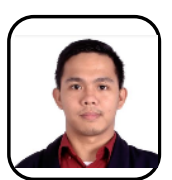

Kyle Bryan A. Maquiso, is a registered Mechanical Engineer of the Republic of the Philippines and a graduate of Bachelor of Science in Mechanical Engineering(2018) in Xavier University-Ateneo de Cagayan, Cagayan de Oro City, Philippines. 